\title{
ОСОБЕННОСТИ ЮРИДИЧЕСКОЙ АНТРОПОЛОГИИ В ИНФОРМАЦИОННОМ ПРАВЕ
}

\section{FEATURES OF LEGAL ANTHROPOLOGY IN INFORMATION LAW}

M. Chapis

Summary. Almost all outstanding anthropologists were lawyers or received a legal education, however, this did not have a particular impact on the development of legal anthropology. The reason is the complexity in defining the invariant determination of law, which was pointed out by I. Kant. Today we know that the informational nature of law is contained in legal information. Analyzing this concept, in this work the author makes an attempt to discover the Kantian apriorism in information law and, for this purpose, explores the anthropological features of the relationship between the legal consciousness of a person and the state as an informational legal order.

Keywords: Homo Juridicus, invariant determination of law, the state as an informational legal order.

\author{
Чапис Максим Анатольевич \\ Аспирант, Институт законодательства \\ и сравнительного правоведения при Правительстве \\ Российской Федерации \\ Mchapis@me.com
}

Аннотачия. Почти все выдающиеся антропологи были юристами либо получили юридическое образование, однако, особого влияния на развитие юридической антропологии это не оказало. В качестве причины называют сложность в определении инвариантной детерминации права, на которую указывал еще И. Кант. Сегодня нам известно, что информационная природа права содержится в правовой информации. Анализируя данную концепцию, в настоящей работе автор предпринимает попытку обнаружить кантовский априоризм в информационном праве и в этих целях исследует антропологические особенности соотношения правосознания человека и государства как информационного правопорядка.

Ключевые слова: Homo Juridicus, инвариантная детерминация права, государство как информационный правопорядок.

гизации современной общественной науки, вновь обретающей свой гуманитарный облик, значительно утраченный на волне увлечения формализованными методами исследования общественных процессов» [2, C. 28].

Итак, предметом современной юридической антропологии является Homo Juridicus - правовой человек, действующий в информационной сфере во множестве своих измерений таких как: человек социальный (Homo Socialis), человек политический (Homo Politicus), человек экономический (Homo Economicus) и т.п. В связи с этим, справедливо утверждать, что объектом юридической антропологии выступает правосознание человека, которое допустимо рассматривать в двух значениях:

1. как одну из форм личного сознания, представляющую собой единую систему правовых теорий, взглядов, идей, формирующих индивидуальное отношение человека к праву (процесс правопознания);

2. как совокупность индивидуальных актов познания права (результат процесса правосознания).

Обе формы правосознания определяются параметрами объектов отраслевой безопасности человека в информационной сфере, основу которых составляет 
то или иное отраслевое измерение правового человека (социальной, политической, экономической безопасности в информационного сфере) и порядком их правового обеспечения.

Проанализировав концепцию А.А.Стрельцова об «информационной модели» человека [3, С. 30-40], мы пришли к выводу, что правосознание - это система правового управления такой моделью, в функции которой входит контроль над обеспечением процесса удовлетворения антропологических потребностей человека в информационной сфере посредством реализации своего права, основу которых составляет «коренная» антропологическая потребность человека - обеспечение своей безопасности.

С указанных позиций человек должен рассматриваться как правовая нейробиологическая информаичонная система управления антропологическими потребностями, а его правосознание - как доминантная структура сознания, качества которой последовательно основываются:

1. на априорности состояния безопасности человека, данной ему в личных ощущениях;

2. относительной автономности правосознания по отношению к иным структурам сознания (интеллекту, воле, чувствам и мотивации);

3. юридизации права в процессе осознания инвариантной правореализации, то есть формализации правосознанием объекта права в строго определенную законом процедуру его обеспечения, в границах которой должна находиться мысль, чьим объектом выступает безопасность.

Перейдем к рассмотрению содержания понятия информационного права.

Информационное право - это система правового регулирования общественных отношений в информационной сфере, и в этом смысле информационное право допустимо рассматривать как науку, изучающую информационный правопорядок общества — «реально существующую упорядоченность общественных отношений» $[5$, С. 25] в информационной сфере.

По мнению И. Канта содержанием права является «априорная форма внешних поступков людей обусловленных априорной формой их внутренних убеждений» [6, С. 612]. Создатель категорического правового императива полагал, что правовые отношения людей подчиняются всеобщему правовому закону: «Поступай внешне так, чтобы свободное проявление твоего произволения было совместимо со свободой каждого, сообразной со всеобщим законом...». По мнению Г.Н. Кругликовой, человеческий разум выражает эту мысль как «постулат, теоретическое доказательство которого невозможно» [20, С. 37].

В одном из своих современных научных пониманий право выступает в качестве «императива, стоящего над государством и законом, призванного защитить справедливый порядок государства как форму самоорганизации общества» [7, С. 130]. Сегодня нам известно, что сущность государства как формы самоорганизации общества составляет система правовой информации, которая берет исток своего формирования в «конфликте интересов участников существующей действительности в виде сигнала о необходимости регулирования общественных отношений и устранения конфликтной среды» [8, С. 177-178]. Справедливость как цель правопорядка допустимо рассматривать в трех значениях: как обеспечение благосостояние человека, как защиту и уважение его свободы и как побуждение его к добродетели [9, С. 5].

Анализ приведенных определений показывает, что правовая информация, прежде всего, характеризуется априорностью правового познания, а ее сущность императивом справедливости как безусловным требованием к человеку, обществу и государству реагировать на соответствующие сигналы и действовать в устранении конфликтов интересов участников существующей действительности не только по соображениям совести и правды, но и в целях взаимного обеспечения свободы и благосостояния.

Общепринятым является представление о том, что «носителем принудительной силы является государство» [20, С. 38], однако исходя из предпосылки о «безусловной справедливости его действия», такая сила также должна подчиняется категорическому правовому императиву. Мы полагаем, что правовым механизмом ограничения принудительной силы государства здесь выступает механизм обеспечения свободы человека. При этом произвести полное теоретическое доказательство этого постулата невозможно, по тем же основаниям, по которым невозможно теоретически доказать необходимость безусловного подчинения человека государству как информационному правопорядку. Оба постулата по своему содержанию априорны, что представляет и информационное право, и государство объектами информационной сферы, обладающими «правовой таковостью» - правовым «сущим, в бытии которого речь идет о самом этом бытии» [21, С. 28].

Внеопытность и категорический императив как основные качества права, соприкасаясь в процессе правового познания, формируют еще одно важнейшее качество права - его инвариантность, то есть внутреннее ощущение человеком неизменности содержания 
правовой нормы при ее использовании и преобразовании под воздействием структур сознания (интеллекта, воли, чувств и мотивации).

Характеризуя структуру объекта, исследователь природы информации А.Д. Урсул подчеркивает, что человек учитывает «не все разнообразие элементов, связей, отношений системы, а лишь нечто устойчивое сохраняющееся» $[12$, C. 83] - ее инвариант. Исходя из этого, можно предположить, что инвариант права представляет собой информационные данные, запечатленные в нейронные структуры головного мозга, сообщающие императивное значение права, осознаваемое априорно. Для подтверждения указанного тезиса проанализируем законодательное определение информации.

В Федеральном законе от 27 июля 2006 г. № 149-Ф3 «Об информации, информационных технологиях и защите информации» указано, информация - это «сведения (сообщения, данные) независимо от формы их представления» $[10$, ст. 2]. Исходя из этого, мы полагаем, что в информационной сфере возможно определить не только атрибутивную и функциональную концепции [см., например, 19, С. 24], но и нормативную концепцию информации. Нормативная концепция информации, по нашему мнению, определяет сущьностное содержание концепциии правовой информацчи.

Дадим характеристику правовым сведениям, сообщениям и данным.

«Сведениями являются запечатленные в человеческом организме результаты отражения движения объектов материального мира» [3, С. 30], использование которых позволяет осуществить выбор варианта наиболее рационального поведения для поддержания условий обеспечения своей безопасности.

Сведения используются как средство адаптации организма к изменениям окружающей его действительности, носят естественное начало, следовательно, являются носителем естественных прав человека и составляют его «информационную модель» [3, С. 30-40].

Исходя из этого можно предположить, что правовые сведения формируют собой атрибутивную концепцию правовой информации, поскольку выражают семантический, то есть смысловой подход, основанный на осознании структуры объекта безопасности в правовом содержании информации.

Правовые сведения формируют статическое правовое измерение информации и выступают смысловым содержанием регулируемых в правовом порядке общественных отношений информационной сферы.
Сообщение - это форма организации и представления сведений в виде:

1. процесса передачи информации как массива информационных данных о разнообразии, значении и смысле объекта,

2. результата такой передачи в пространстве и времени.

Как категория реальности сообщение является символом информации [8, С. 103]. Символ - это то, что служит условным знаком какого-либо понятия. Знак - это информационный объект, используемый для передачи смысла этого понятия.

Правовые сообщения составляют функциональную концепцию правовой информации, выражают синтаксический, то есть основанный на коммуникации подход к обеспечению безопасности, и формируют динамическое правовое измерение информации, основной функцией которого является формирование государства как информациионного правопорядка.

«Данные - это суть информации» [17, С. 28] - то, «что может существовать объективно» [18, С. 26]. Правовые данные - это суть правовой информации «как единого трансляционного акта правовой действительности, объективизирующегося путем сложных интроспективных преобразований правотворческого типа в отображаемый в правосознании образ» [8, С. 19] правовой объект сознания.

Анализ содержания системы правосознания показывает, что правовые объекты как фундирующие элементы правосознания могут быть двух типов (перманентные и временные) и двух видов (востребованные и невостребованные).

Перманентные правовые объекты сознания - это объекты правопознания, проистекающие из основных прав и свобод человека (например, право на жизнь).

Временные правовые объекты сознания - это объекты правопознания, проистекающие из специальных правовых статусов субъектов информационной сферы (например, правовой статус государственного служащего).

Правовые объекты сознания могут быть двух видов: востребованные в настоящий момент (например, право на жизнь - это перманентное востребованное право) и невостребованные, но объективно существующие в настоящий момент. Невостребованные правовые объекты, как правило, истребуются сознанием в связи с возникновением определенных условий: например, 
если человек решает, что его субъект тождественен субъекту невостребованного им до настоящего момента права, то «спящий» правовой объект сознания под воздействием механизмов правосознания - главным образом слова и внутренней суверенной речи - превращается в пробужденный объект правосознания (например, в право на назначение и выплату обеспечения по страхованию).

Отметим внутреннюю динамику указанного процесса. Ощущение в сознании данности правового объекта возникает у человека как ощущение предзаданности опыта его познания. Уже упомянутое право на жизнь обычно не требует специального правового обоснования. Оно просто существует как логико-правовой источник для всех остальных прав. Результат правового познания такого объекта предзадан. Априорность права здесь ощущается как некая антропологическая максима в праве, содержанием которой является самоочевидное правило поведения человека. Само ощущение данности права на жизнь априорно, то есть как бы предустановленно в человеческом сознании и является исходной логико-правовой основой для развертывания мысли об обеспечении его безопасности.

Ощущение априорности объекта правосознания снимает информационно-правовую неопределенность в сознании и обнаруживает человека один на один с его антропологической потребностью, которую он сможет удовлетворить только, если посчитает что у него на это есть право. Иными словами, если ощутит априорность данности его права. И только после этого в сознании познающего возникает инвариантность права, качество, которое, по нашему мнению, обеспечивает способность права выступать регулятором общественных отношений, делая их материальными и способными фундировать собой любые информационные процессы.

«Я знаю о правовом объекте то, что я знаю. Это знание является для меня исчерпывающим, поэтому я буду действовать в удовлетворение антропологической потребности определенным образом, так как иного выбора в обеспечении своей безопасности у меня нет»,- Согласно такой логике в сознании возникает некое «право на право». Этот процесс составляет собой трансформацию правового объекта сознания в объект правосознания, побуждая человека к инвариантным действиям. Мы полагаем, что в антропологическом значении права как в одной из своих научных детерминаций, таким «правом на право» является информационное право.

Учитывая изложенное, нормативную концепцию правовой информации справедливо представлять $n p a$ - вовыли даннылми как инвариантным видом правовой информации, то есть такой информации, содержание которой остается неизменным при своем преобразовании и использовании.

Инвариантность составляет правовое измерение информационного объекта, сущностью которого, прежде всего, является сам факт его объективного существования. Мы полагаем, что, с точки зрения классического правового позитивизма, рассматриваемая концепция является строго правовым пониманием информации, характеризует собой «ядерную» сущность информационного права, представляя его объект как совокупность правовых данных.

Следовательно, возможно допустить, что информационные данные в праве формируют нормативно-правовое измерение информационной сферы, структуру которого составляют правовые данные, существующие как объект человеческого сознания в форме инвариантных сведений, формализованных посредством правовых сообщений в норму информационного права, чьим объектом выступает обеспечение безопасности.

Атрибутивная и функциональная концепции информации являются классическим представлением информации как междисциплинарного понятия и их содержание естественно сообщает праву качества информации. Первая концепция сообщает праву природу информации: ее нематериальность, неотчуждаемость, неуничтожимость, обособляемость, субстанциональную несамостоятельность, непотребляемость [11, С. 16-17]. Вторая - саму сущность информации: - нести отражение, различие, разнообразие правовых объектов информационной сферы [12, С. 8, 57-70].

В силу имманентного доминирования качеств априорности и инвариантности права, нормативная концепция правовой информации подчиняет себе атрибутивную и функциональную концепции правовой информации, таким образом формируя два основных нормативно-правовых измерения информационной сферы: нормативно-атрибутивное правовое измерение информационной сферы, являющееся источником правовых смыслов, и - нормативно-функичинальное правовое измерение информационной cферы, определяющее порядок их обретения. Мы полагаем, первое измерение является совокупностью информационных объектов, а второе - системой правовых механизмов обеспечения их безопасности.

Однако следует учитывать, что понятие «правовая информация», как и само понятие «информация» представляет собой «абстрактную модель» [8, С. 103] и является собирательным понятием. В связи с этим 
в правовом пространстве информационной сферы целесообразно различать такие понятия как: «правовые сведения», «правовые сообщения» и «правовые данные», выступающие различными элементами процесса правового познания по функциональному критерию.

При этом особому разделению должны подлежать такие понятия как «правовая информация» и «правовое знание». Правовая информация всегда несет в себе лишь некий информационный фрагмент, всегда лишь некую долю осведомленности о структуре объекта права, в отличие от правового знания, которое по своей сути есть понимание права и поэтому всегда имеет исчерпывающий объем по факту своего возникновения.

Исходя из вышеизложенного, можно сделать вывод о том, что непознанное право для человека является отсутствуюшим, а познанное для него - инвариантно, то есть неизменно при дальнейшей информационной обработке правового содержания его объекта.

Как указывает Е.М. Чинарян, «осознание мира происходит только (курсив наш.-М.А.) с помощью слова, именно слово является материалом мысли, соотношение между мыслью и словом - это соотношение между содержанием и формой» [13]. Учитывая это, допустимо считать, что слово выступает мерой правосознания и с этой точки зрения его допустимо рассматривать как основной механизм обеспечения безопасности в информационной сфере.

Система словесного выражения мыслей представляет собой язык. В контексте правосознания задачей языка является выражение правовой воли через осознание, интерпретацию и использование сведений и данных правовой мысли. Такое выражение происходит посредством правового сообщения - сообщения особого инвариантного вида, правовое содержания которого остается неизменным при своей передаче. В связи с этим человеческий мозг может быть представлен как нейробиологическая информационная система конвертации правовых сведений в правовое знание посредством правовых сообщений. Функцией такой системы является осознание инвариантности права применительно к конкретной структуре информационной сферы (факту, событию, явлению, условию и т.д.).

Человек конструирует субъективную реальность при помощи информационных фреймов ${ }^{1}[16]$ сам из себя подобно тому, как паук плетет паутину из секрета своих внутренних желез (аутопойезис). Результатом такого

Фрейм - понятие гуманитарной науки, обозначающее целостность, в рамках которой люди осмысливают себя в мире самопостроения является нейробиологическая информачиионая сеть человеческого мозга с постоянным движением потока информационных данных внутри нее. В системе правосознания указанные процессы существуют как логико-языковой анализ доступных человеку правовых фреймов сознания и зависят от его когнитивных способностей извлекать из атрибутивного содержания таких фреймов новый функционал в обеспечение своей безопасности. При этом следует указать, что такой процесс всегда детерминирован возможностями правового языка и объемом правового тезауруса, которыми владеет человек.

Природа всегда являлась и всегда будет являться для Homo Sapiens источником информации поскольку с помощью информации человек не только осознает себя и свои взаимоотношения с окружающим его миром, но и обеспечивает свою безопасность в информационной сфере.

Антропологическая закономерность развития человека как Homo Socialis такова, что к моменту возникновения понимания концепции права система человеческого языка должна быть развита достаточно, чтобы оказаться способной передать априорную инвариантность, которую человек ощущает внутри как смысловое содержание понимания своей безопасности, а затем и понимания права. Такая передача может осуществляться третьим лицам, а может - для самоосознания, то есть для понимания субъектом своего отношения к тому или иному объекту права.

Правовой смысл нормы права должен быть познан в контексте субъективной реальности, что предполагает материализацию его смысла в словах применительно к конкретной ситуации. Ведь такое право прежде всего должно быть объяснено словами и в этом смысле объективизировано как структура правосознания.Руководствуясь изложенным, мы полагаем, что перцепция состояния безопасности субъекта информационной сферы первична по отношению к перцепции состояния его информационного права.

Исходя из этого, справедливо полагать что любая норма информационного права всегда включает в себя и соответствующую норму права информационной безопасности как свой «коренной» источник, за которым стоит мера правосознания, которая определяется мыслью, формируемой посредством слова, как основным правовым механизмом определения меры обеспечения безопасности человека в информационной сфере.

В заключение нужно сказать о том, что основной особенностью юридической антропологии и информационного права является обнаружение в центре обеих наук человека как источника и средоточия любой 
правотворческой деятельности. Более того, предмет рассматриваемых наук неразрывен, так как невозможно разделить Homo Juridicus и, например, Homo Economicus как различные информационные измерения одного и того же человека.

Неразделимость человека в условиях его правовой многомерности в информационной сфере превращает юридическую антропологию в науку сверхъюридического характера [4, С. 82], а информационное право в суперотрасль права [14, С. 30-31]. В связи с этим мы полагаем, что Homo Juridicus как субъект информационной сферы, всегда должен рассматриваться и как Homo Informaticus.

Как указывает Ф.А. Черданцев, «в правовом регулировании нет влияния материи на материю. Оно проявляется в воздействии мысли, подкрепленной волей, на сознание мыслящих и обладающих волей субъектов» $[15$, С. 10].

Поскольку идеальные объекты обретают материальную форму с помощью языка [15, С. 13], генезис нормы права как первичного элемента права происходит в форме мысли, выраженной словами, обозначающими конкретные юридические термины и понятия. Этот процесс составляют «два параллельных, одновременных потоках информации: о фактах и о нормах» [15, С. 26].

Формой самой правовой мысли выступает фрейм сознания - технология умозрительного моделирования, которая применяется для обобщения информации, ее интерпретации, объяснения для кодирования и раскодирования речевых сообщений, содержащих информацию о правовых фактах и нормах, применяемую человеком в целях обеспечения своей безопасности.

Эти обстоятельства дают нам все основания представить норму информационного права инвариантной формой человеческой мысли о безопасности, содержание которой предопределяется перцептивным априоризмом состояния безопасности в информационной сфере.

Суммируя изложенное, можно сделать следующие выводы.

Во-первых, состояние безопасности человека как биосоциального существа достигается посредством использования информации различных видов, типов, форм и отраслевого содержания, однако механизмом обеспечения безопасности такой информации всегда будут выступать правовые данные как особый (априорный, инвариантный) вид правовой информации, составляющий структуру нормы информационного права как правового фрейма человеческого сознания.

Во-вторых, норма информационного права в своем антропологическом значении представляет собой мысль человека о безопасности, возникающую как процесс обработки структурами сознания поступающей от внешних источников информации в понимаемую конкретным человеком как адресатом такой нормы меру своей безопасности, формирующуюся, словом, как основным правовым механизмом определения такой меры в информационной сфере.

В-третьих, государство как объект информационной сферы представляет собой логико-языковой феномен правового сознания человека, содержание которого предопределено биологическими мутациями головного мозга и заключено в его нейронные структуры как знак информационного правопорядка, функцией которого является сообщение человеку правовой механики обеспечения его права и безопасности, основу которой составляет безусловное требование действовать по соображениям совести и правды во имя справедливости и добродетели.

\section{ЛИТЕРАТУРА}

1. Рулан Н. Юридическая антропология. Учебник для вузов. “Перевод с франц. Ответственный редактор — член-корр. РАН, доктор юридических наук, профессор В.С. Нерсесянц.- М.: Издательство НОРМА, 1999. — 310 с.

2. Ковлер А.И. Антропология права: Учебник для вузов.—- В,: Издательство НОРМА (Издательская группа НОРМА-. ИНФРА М), 2002.

3. Стрельцов А.А. Теоретические и методологические основы правового обеспечения информационной безопасности России Диссертация на соискание степени доктора юридических наук, Москва, 2004. - 371 с.

4. Дробышевский В.С. Право в российской культуре: проблемы социальной методологии Диссертация на соискание ученой степени доктора философских наук, Чита, 1998. - 319 с.

5. Общее учение о правовом порядке: восхождение правопорядка: монография. Т. 1 /Н.Н. Черногор, Д.А. Пашенцев, М.В. Залоило [и др.]; отв. ред. Н.Н. Черногор.—- М.: Институт законодательства и сравнительного правоведения при Правительстве Российской Федерации: ИНФРА-М, 2019. — 348 c.

6. Кант И. Собрание сочинений: в 8 т. Т. 6: Религия в пределах только разума; Метафизика нравов / под общ. ред. А.В. Гулыги. М.; 1994

7. Лопатин В.Н. Информационная безопасность России Диссертация на соискание степени доктора юридических наук Санкт-Петербург 2000. $433 c$. 
8. Кузнецов П.У. Теоретико-методологические основания информационного права Диссертация на соискание степени доктора юридических наук, Екатеринбург, 2005.- $410 \mathrm{c}$.

9. Сэндел М. Справедливость. Как поступать правильно? /Майкл Сэндел; пер. с англ. Александра Калинина.—М.: Манн, Иванов и Фербер, 2013. — 352 с.

10. Федеральный закон “06 информации, информационных технологиях и защите информации” от 27.07.2006 № 149-Ф3

11. Терещенко Л.К. “Правовой режим информации” Диссертация на соискание степени доктора юридических наук, Москва, $2013,-415$ с.

12. Урсул, А.Д. Природа информации: философский очерк / А.Д. Урсул; Челяб. гос. акад. культуры и искусств; Науч. — образоват. центр“Информационное общество"; Рос.гос. торгово-эконом. ун-т; Центр исслед. глоб. процессов и устойчивого развития. 2-е изд.— Челябинск, 2010.— 231 с.

13. Чинарян Е.М. Язык как средство выражения правовой мысли. Особенности языка законодательства. Журнал Право и государство: теория и практика № 12020

14. Кузнецов П.У. Теоретические основания информационного права Автореферат диссертации на соискание степени доктора юридических наук, Екатеринбург, 2005. - 58 с.

15. Черданцев А.Ф. Логико-языковые феномены в юриспруденции: монография / А.Ф. Черданцев.— М.: Норма: ИНФРА-М, 2012.— 230 с.

16. Гофман И. Анализ фреймов: эссе об организации повседневного опыта: Пер. с англ. /Под ред. Г.С. Батыгина и Л.А. Козловой; вступ. статья Г.С. Батыгина. М. Институт социологии РАН, 2003. - 752 c.

17. Мартиросян Т.А. Правовое обеспечение информационной безопасности Российской Федерации Диссертация на соискание степени кандидата юридических наук Москва, 2005. - 210 c.

18. Гольтяпина И.Ю. Административно-правовые средства обеспечения информационной безопасности в России Диссертация на соискание степени кандидата юридических наук Омск, 2008. - 235 с.

19. Минбалеев А.В. Система информации: теоретико-методологическое исследование Диссертация на соискание степени кандидата юридических наук, челябинск, 2006. - 272 с.

20. Кругликова Г.Г. Проблема человека в философии Иммануила Канта и философско-педагогических концепциях русских мыслителей второй половины XIX-первой трети XX века Диссертация на соискание степени кандидата философских наук, 2002. - 137 с

21. Хайдеггер М. Бытие и время / М. Хайдеггер; Пер. с нем. В.В. Бибихина.—Харьков: «Фолио», 2003.— 503 с

(c) Чапис Максим Анатольевич ( Mchapis@me.com ).

Журнал «Современная наука: актуальные проблемы теории и практики» 